\title{
Characterization and Enhancement of Microbial Biodiversity in Digestate in the Agronomic Field
}

\author{
Giuliana Conversano, Graziano Pizzolante, Pietro Alifano and Luigi De Bellis \\ Dipartimento di Scienze e Tecnologie Biologiche e Ambientali, Università del Salento, Via Prov.le Lecce-Monteroni, Lecce 73100, \\ Italy
}

Received: March 3, 2015 / Accepted: April 18, 2015 / Published: April 30, 2015.

\begin{abstract}
The possibility of producing biogas and methane from two phases olive pomace was considered using anaerobic digestion and the microbial characteristic of digestate for the agrarian use was analyzed. In the work, the main aim was to obtain biogas, made from at least $50 \%$ methane, and a digestate that can be used in the field of agronomy, from the anaerobic digestion of the substrates. The tests were carried out by digesting different mixtures of the two-phase pomace, mulberry leaves and mud civil wastewater (pre-digested) in a batch system and in anaerobic mesophilic conditions $\left(35^{\circ} \mathrm{C}\right)$. The substrates were properly homogenized in order to obtain mixtures of known and uniform composition. The initial and final STi (Total Solids) and initial SVi (Volatile Solids), the concentration of chemical oxygen demand and total phenols were measured and the process yield (m3/t SV) was quantified with standard procedure. The objectives of the study were the analysis of microbial biodiversity developed during fermentation of mixtures based products and the microbial communities corresponding to Eubacteria, Archaea and Fungiwas analyzed. The suitability of the digestate for agronomical use was evaluated by estimating pathogens bacteria that may be present and by index of inhibition of plant organisms model.
\end{abstract}

Key words: Olive pomace, anaerobic digestion, Methane, digestate, microbial community.

\section{Introduction}

Following the energy crisis of the 70 s concerns about the availability of renewable energy sources, considered alternatives to traditional fossil sources have increased. To limit $\mathrm{CO}_{2}$ emissions and combat climate change, industrialized countries have initiated innovative energy plans [1]. New renewable sources were investigated and biochemical processes were developed. Many sources, such as crops, grasses, leaves, manure, fruit, and vegetables waste have been used and the process has been applied in small and large scales [2].

Anaerobic decomposition of organic compounds is conducted in close cooperation with specialized microorganisms of different type, including mostly hydrolyzing, acidifying, acetogenic, and

Correspondigauthor: Giuliana Conversano, Ph.D., research fields: ecology and climate changes. E-mail: giuliana.conversano@unisalento.it. methanogenic one. The final stage of the digestion process produces biogas, containing $\mathrm{CO}_{2}$ and $\mathrm{CH}_{4}$ [3].

Anaerobic digestion of energy crops, residues and wastes is of increasing interest in order to reduce the greenhouse gas emissions and to facilitate a sustainable development of energy supply. The success of the biogas production will come from its availability at low costs and the broad variety of usable forms of biogas for the production of heat, steam, electricity and digestate for agronomic use [2].

Salento as Puglia is an area with a high production of olive oil. The choice of subjecting olive pomace to the anaerobic fermentation, is a compromise between the need to dispose of a by-product of difficult management downstream, and concomitant production of biogas rich in methane and convertible into electricity and heat [4]. But the amount of phenols that characterizes the two-phase pomace is significantly greater and it can lead to low yields of 
anaerobic processes because of their inhibitory action [5]. In literature there are several studies in which different matrices are used, often in co-digestion, that will produce different results [6]. Fantozzi et al. [7] analyzed the process yields with different matrices: the comparison between two mix in which the same substrate is used, i.e. the pomace, with different co-substrate as inoculum (slurry and manure from different animal nature), showed how the substrate, if coupled with an inoculum as swine manure anaerobically predigested, offered good yields in terms of biogas production and methane.

Through a careful analysis of the advantages and disadvantages of using the anaerobic digestion substrate in two phases not pretreated in co-digestion with other substrates, it is possible to make estimates on the feasibility of the process in environmental, economic, legal, and social terms [8].

The process of co-digestion is aimed at using of biomass of various types subjected to the same process of anaerobic digestion. This mode of digestion allows to obtain significant results in the benefit about yields of the process of environmental protection.

Manure, municipal wastewater and the organic fraction of municipal solid waste increase yields of methane, they are rich in microorganisms useful to the process, which is why they become good adjuvants in co-digestion systems in which they operate in the "start-up" phase of the process [9]. In some cases, the effectiveness of the production mix choice for co-digestion, proves discarding the possibility of a pre-treatment in order to optimize the process [10]. This saves on costs due to any pre-treatment to be applied to the incoming item in order to facilitate biomass degradation.

Creating biomass heterogeneous mix of different nature and considering the nutrients that are in there, a relationship of constant concentration to the required values can be established.

The use of biomass in different co-digestion allows to "balance" the $\mathrm{pH}$ to the desired value for the succeeding of the process, registering higher values of yield: Zhang et al. [11], conducted an experiment in batch system to two phases (hydrolysis and acid genesis which are distinct in space and time) subjecting kitchen substrates with different $\mathrm{pH}$ values to anaerobic digestion; the analysis of their compared yields of methanogenic mix at different $\mathrm{pH}$, highlighted how the achievement of an optimal $\mathrm{pH}$ value $(\mathrm{pH}=7)$ ensured higher yields.

Furthermore, the microbial community structure influences the process stability and the biogas yield and it requires further efforts and it must be analyzed in more details. Recent studies have demonstrated that strong variations in the community structures occur during the fermentation which influences the process efficiency. Molecular analyses have shown the presence of numerous recently unknown bacteria which may have an important influence on the degradation process [2]. For this purpose, in the work the authors analyzed by culture-independent approach, the microbial community of digestate. In addition, they calculated the number of pathogenic bacteria present in this product.

The anaerobic digestion process occurs in reactors called digesters which are properly designed and, that will produce as final products a mixture of gases known as biogas, and a digestate from soil properties that makes this biomass output, a good resource in the agronomic field [12] .

The anaerobic digestion process results in a mineralization of organic nutrients, in particular nitrogen, and in a lowering of the $\mathrm{C} / \mathrm{N}$ ratio. The digestate allows an accurate dosage and integration in a fertilization plan with a reduced application of additional mineral nitrogen fertilizers. The digestate can penetrate faster in the soil, and reduces the risk for nitrogen losses by ammonia emissions. Anaerobic digestion also results in a significant reduction of odors [2]. The anaerobic digestion process is able to inactivate weed seeds, bacteria (e.g. Salmonella spp., Escherichia coli, Listeria spp.) viruses, fungi and 
parasites in the feedstock which is of great importance if the digestate is used as fertilizer [13]. The decay rate depends on temperature, treatment time, $\mathrm{pH}$ and on volatile fatty acid concentrations. A $90 \%$ reduction of a Salmonella population is achieved at a thermophilic temperature $\left(53{ }^{\circ} \mathrm{C}\right)$ within only $0.7 \mathrm{~h}$ whereas in mesophilic conditions $\left(35^{\circ} \mathrm{C}\right)$ at least 2.4 days are necessary [14]. For specific wastes, a separate pasteurization before or after the anaerobic digestion at $70{ }^{\circ} \mathrm{C}$ for $60 \mathrm{~min}$ is stipulated by the European Union Animal By-Products Regulation [15]. Pasteurization is an effective way of heat treatment, but bacterial spores are not reduced. Moreover, the digestate is particularly prone to recontamination.

In the work, the original digestate from anaerobic digestion of olive pomace, mud civil wastewater (previously anaerobic digested) and vegetable biomass was tested. The digestate was directly used for the germination test. It is diluted with sterile water but none of the treatment is effectuated and the effective present charge bacteria and \% inhibition of plants model were measured.

\section{Materials and Methods}

\subsection{Biogas and Methane Production}

The system used to conduct the experiments of the anaerobic digestion has been manufactured by RES of Ravenna. It allows to perform digestions in batches (batch method), completely (or continuously) mixed (CSTR , Continuously Stirred Tank Reactor) and it is composed of two anaerobic reactors, an electrical panel and a computer.

The biogas produced was subjected daily, and several times a day, to the analysis by Gas Analyzer Geotech, in order to determine the proportion of methane, carbon dioxide, oxygen and "BAL" (expressed as \% of Total Gas balancing, $\mathrm{NH}_{3}, \mathrm{~N}_{2}$, $\mathrm{H}_{2} \mathrm{~S} \ldots$ ) in the biogas produced during the anaerobic digestion process.

Data on the volume of the biogas produced were obtained by detecting the pressure probe and reworking the software provided by the RES company, and they were verified manually: Aspiration with syringe calibrated biogas accumulated in the bag, it was verified that the daily volume of biogas daily recorded by the software was the same as that taken manually. The quality of the biogas was instead monitored by analyzing the percentage of the species of gas, using the portable biogas analyzer.

The mixtures used in the tests of the anaerobic digestion, therefore, consist of two-phase pomace, civil wastewater sludge, mulberry leaves and water in different concentrations for a total volume of $4.5 \mathrm{~L}$.

The breakdown percentage of TS (Total Solids \% ), SF (Fixed Solids \%) and SV (Volatile Solid \%) of masters and mix at the beginning and the end of the fermentation were determined by protocol derived from the Standard Method 1684.

COD (Chemical Oxygen demand) determination of the mix at the beginning and end of fermentation was obtained by Test NANOCOLOR COD 15000 in accordance with UNI ISO 15705 .

The concentration of Total Phenols was determined by the Folin-Ciocalteu [16].

\subsection{Rate of Germination in Plant Organisms Model}

To determine the rate of the inhibition of germination and root elongation rate in Cucumissativus, Lactuca sativa and Avena sativa to the rate of germination was applied by the method APAT 3544, 2003.

The seeds of two cotyledons and a monocotyledon were exposed to the sample and incubated in the dark at a temperature of $25^{\circ} \mathrm{C}$ for $72 \mathrm{~h}$. After exposure, the seeds germinated are counted and by using of a ruler, the length of the root emerged from the seeds was measured. The effect on germination and root elongation is expressed as \% GI (germination index \%) in reference to the control (distilled water). Using a statistical method also it determines if the sample has a bio-stimulation or inhibition (II \%).

The results obtained were processed using the 
statistical program for calculating R (software project of statistical computing).

\subsection{DNA Procedures and Generation of PCR-SSCP Genetic Profiles}

Total genomic DNA was extracted from the digestate samples at the beginning and the end of the fermentation phase using the Power soil ${ }^{\circledR}$ DNA isolation kit (MO BIO Laboratories) according to the manufacture's instructions. For SSCP (single-strand conformational polymorphism) analysis, genomic DNA was used as template in PCRs (polymerase chain reactions) in order to amplify respectively genes coding for 16S rRNA (for Eubacteria and Archaea) and 18S rRNA (for Fungi). The primers pairs used for PCRs are: Com1-F and Com2-R [17] (for Eubacteria), W36-F and W34-R [18] (for Archaea), FUN18S1-F and FUN18S2-R [19] (for Fungi). PCR products were separated by electrophoresis through $1 \% \quad(\mathrm{w} / \mathrm{v})$ agarose gel in 1X TAE (Tris-acetate-EDTA) buffer [20] and purified by using a Qiaex II DNA purification kit. $9 \mu \mathrm{L}$ of purified samples were denatured by adding $12 \mu \mathrm{L}$ of formamide loading buffer $(80 \%[\mathrm{wt} / \mathrm{v}]$ deionized formamide, $10 \mathrm{mM}$ EDTA [pH 8], $1 \mathrm{mg} / \mathrm{mL}$ xylene cyanol FF, $1 \mathrm{mg} / \mathrm{mL}$ bromophenol blue) at $95{ }^{\circ} \mathrm{C}$ for $5 \mathrm{~min}$ and then resolved by $10 \%$ polyacrilamide (29:1) gel electrophoresis in $0.8 \mathrm{X}$ TBE (Tris-borate-EDTA) buffer at $25 \mathrm{~mA}$ and $4{ }^{\circ} \mathrm{C}$. Gels were silver stained according to standard procedures [20].

\subsection{Sequence Analysis of Products from SSCP Microbial Community Profile}

All bands identified in SSCP polyacrilamide gels were excised with a razor blade. Then, blocks of gel were transferred in $50 \mu \mathrm{L}$ of sterile water, and the DNA was allowed to diffuse overnight at $4{ }^{\circ} \mathrm{C}$. The eluted DNA was reamplified with the same primers and PCR conditions described for PCR-SSCP analysis. PCR products were further tested by SSCP for purity and identity with the original bands in the community profiles and then cloned in pGEM T-easy vector Promega ${ }^{\circledR}$. Sequencing will be discussed in a future publication.

\subsection{Determination of the Pathogenic Charge of Digestate}

In order to determine the charge of the pathogenic species present in the digestate, the authors tested the growth ability of E. coli and Salmonella spp. on suitable selective media following Regolamento CE $\mathrm{n}$. 1069/2009 and subsequent modifications.

\section{Results and Discussion}

\subsection{Comparison of Biogas and Methane Production}

By analyzing the daily biogas produced in each test it was possible to evaluate the performance of the process in terms of methane production with respect to the other gases present in the overall mixture (Fig. 1).

It was shown that the mix containing sludge civil wastewater, two-phase olive pomace and dried leaves of mulberry (VS Total mix $=358.5 \mathrm{~g}$ ), produced a good yield of biogas and methane in 40 days of fermentation (Figs. 2 and 3). Furthermore, it acted as inoculum, because it provided a methanogenic microbial population adapted to grow/survive in the presence of this substrate. This mix demonstrated to can be effective to start further fermentations.

Tests of the process optimization showed a stable performance in terms of $\mathrm{pH}$ (Table 1), and a good rate of COD reduction (on average of 70\%), the Total phenols (on average of $65 \%$ ) and Volatile Solids (on average of $90 \%$ ). In particular, the mix B, which contained the inoculum taken from $\mathrm{A}$ in an exponential phase, was the test faster and the more efficient tests and it has produced higher yields of biogas and methane, expressed in $\mathrm{m}^{3} /$ ton of Volatile Solids and $\mathrm{m}^{3} /$ ton of original pomace (Table 1). In literature there are few studies reporting data on the fermentation substrate which is not pretreated [21]. Almost all works report the fermentation substrate 


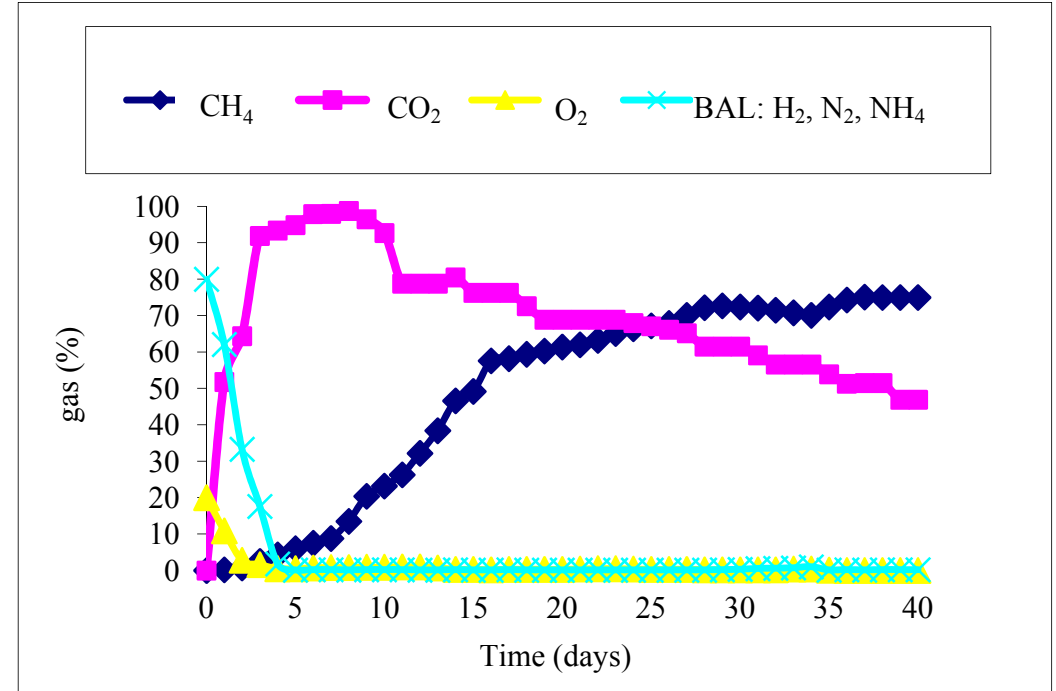

Fig. 1 Percentage of gases present in the biogas produced (Test A).

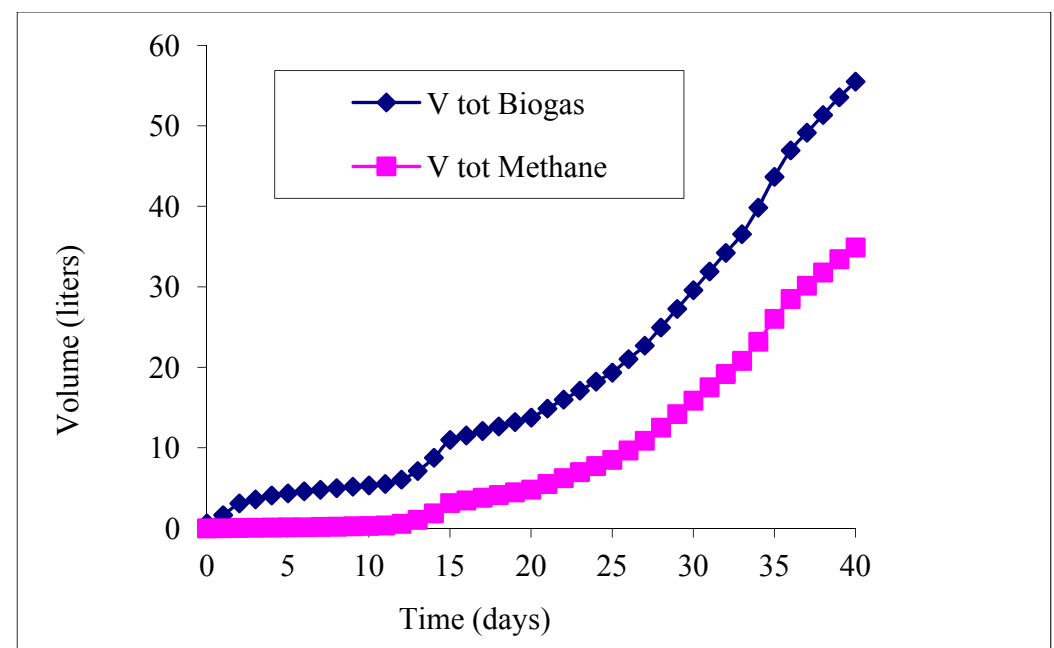

Fig. 2 Cumulative production of biogas and methane (Test A).

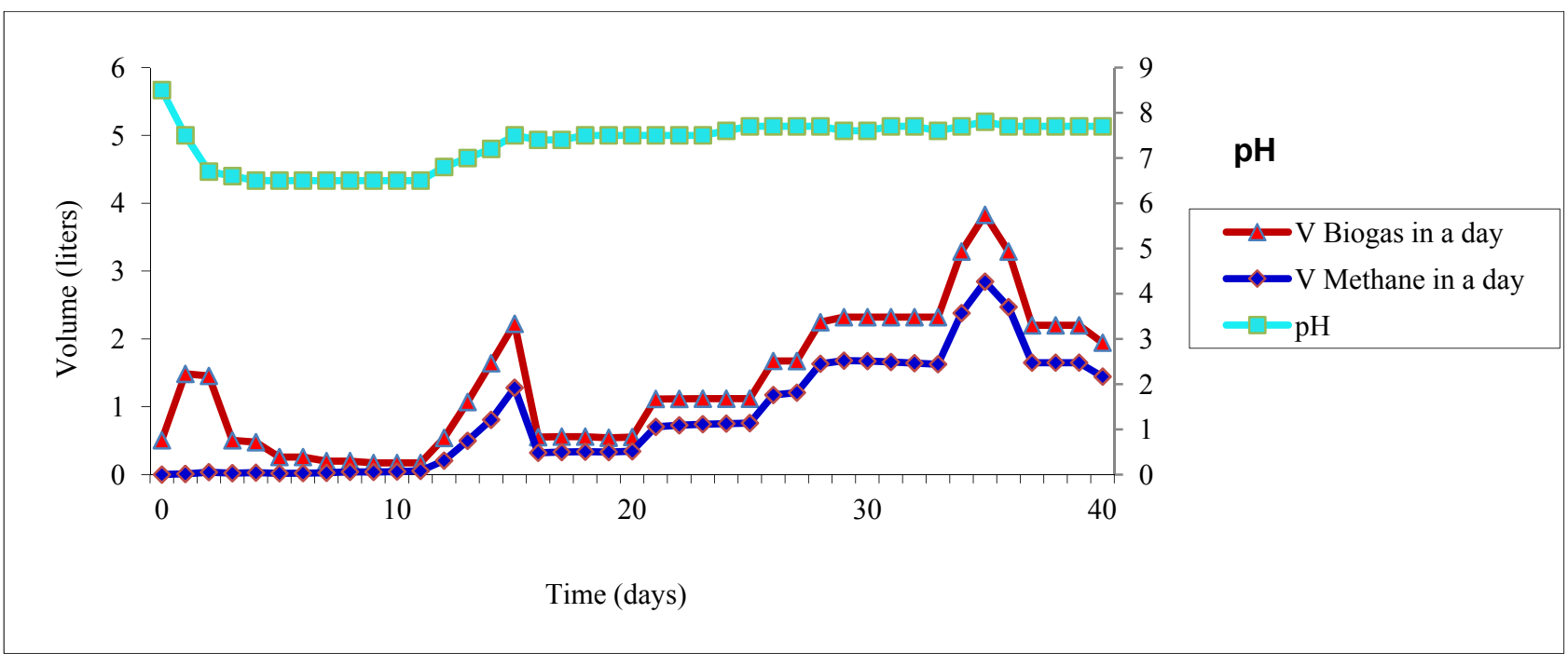

Fig. 3 Daily production of biogas and methane and pH line (Test $\mathrm{A})$. 
Table 1 Results of three tests A, B and C.

\begin{tabular}{lllll}
\hline MIX & $\mathrm{pH}($ medium $)$ & Initial VS tot $(\mathrm{g})$ & Yield Biogas $(\mathrm{m} 3 / \mathrm{t} \mathrm{VS})$ & Yield Methane $\left(\mathrm{m}^{3} / \mathrm{t}\right.$ VS) \\
\hline A & 6.8 & 358.5 & 154.5 & 97.0 \\
$\mathrm{~B}$ & 7.3 & 433.8 & 208.8 & 129.0 \\
$\mathrm{C}$ & 6.6 & 408.8 & 183.3 & 116.6 \\
\hline
\end{tabular}

Table 2 Comparison with the theoretical yields reported in literature.

\begin{tabular}{ll}
\hline References & $\begin{array}{l}\text { Yield Methane } \\
\mathrm{m}^{3} / \mathrm{t} \mathrm{SV}\end{array}$ \\
\hline Danieli e Aldrovandi, L'Informatore Agrario, 2011 (olive pomace) & 204 \\
Soldano et al., Ecomondo, 2011, CRPA Reggio Emilia (olive pomace) & 182.8 \\
& 110 \\
Fantozzi e Buratti, Bioresource Technology, 2009 (olive pomace) & 30 \\
Rossi e Piccinini, Ecomondo, 2010, CRPA Reggio Emilia (sludgewastewater) & 186 \\
& 157 \\
Razaviarani et al., 2013 (sludgewastewater) & 180 \\
\hline
\end{tabular}

in co-digestion with other substrates and initiate the reaction with pretreatment of substrates or with the use of a nutrient solution of ignition and synthetic starter (Table 2). However, a comparison can be set with the data regarding the yields of methane expressed in $\mathrm{m}^{3} / \mathrm{t}$ VS and it demonstrated that the substrate was digested in two phases during the tests studied in this work and it produced methane.

\subsection{Analysis of the Microbial Community of Digestate by Culture-Independent Methods.}

To investigate the quantitative species composition and the temporal dynamics of the digestate microbial community during a 40-day digestion cycle in three independent experiments, a time course profiling of partial domains of the eubacterial/archaeal 16S rRNA and fungal 18S rRNA was performed by SSCP. SSCP is a technique that provided a meaningful picture of the microbial community evolution during a process. As shown in Figs. 5 and 6, the microbial community varied depending both of the mix and of the digestion step. At initial step, several species of Ei (Eubacteria) were significantly present in all three examined samples; whilst Fi (Fungi) and Ai (Archaea) were more abundant in $\mathrm{B}$ and $\mathrm{C}$ mixes compared to $\mathrm{A}$. At final stage of the digestion process, the authors noted an increase of the Ef (eubacterial species) with respect to the initial stage of all three mixes. In addition, it was evident an increase of the Ff (fungal species) in B and $\mathrm{C}$ mixes and an increase of Af (archaeal specie) only in A mix. In future, the authors will provide to gain additional information about the identification of microbial species detected with SSCP analysis.

The microbial population colonizing the substrate typically consists of predominantly Alphaprotobacteria, Firmicutes, Gammaproteobacteria, and the yeasts Candida, Pichia, Saccharomyces and, in anaerobic conditions, Clostridium, and Chloroflexi Methanosaeta, as described by Ntougias et al. [22].

Rincon et al. [23] analyzed the microbial community which is present in a bioreactor during the two-phase pomace anaerobic digestion. The groups represented are: Firmicutes $(53.3 \%$ of the sequences analyzed) mainly consist of Clostridium; Chloroflexi follows to $23.4 \%$, the Gamma proteobacteria (8.5\%, mainly belonging to the genus Pseudomonas); Actinobacteria 6.4\% and 4.3\% Bacteroidetes. Among the Archaea found in this anaerobic system there are Methanosaeta concilii, a methanogenic acetoclastic, which is very common in the stable anaerobic systems and often represents the largest component of the methanogenic community. In literature it has been reported that sintrofic stable relations between Methanosaeta and Bacteria are easily created. Ntougias et al. [22] states 


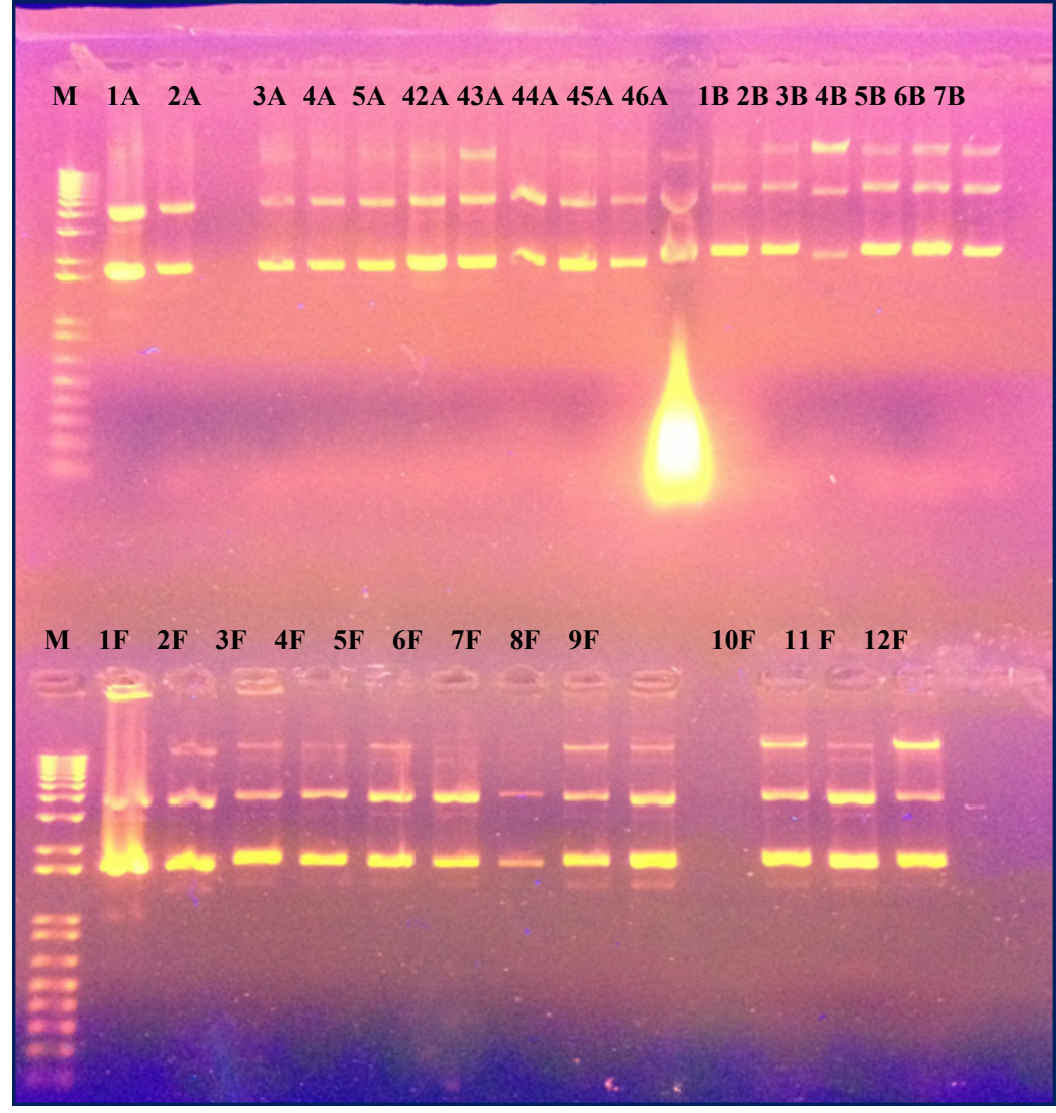

Fig. 4 Visualizing of the DNA sequences selected through miniprep from clones.

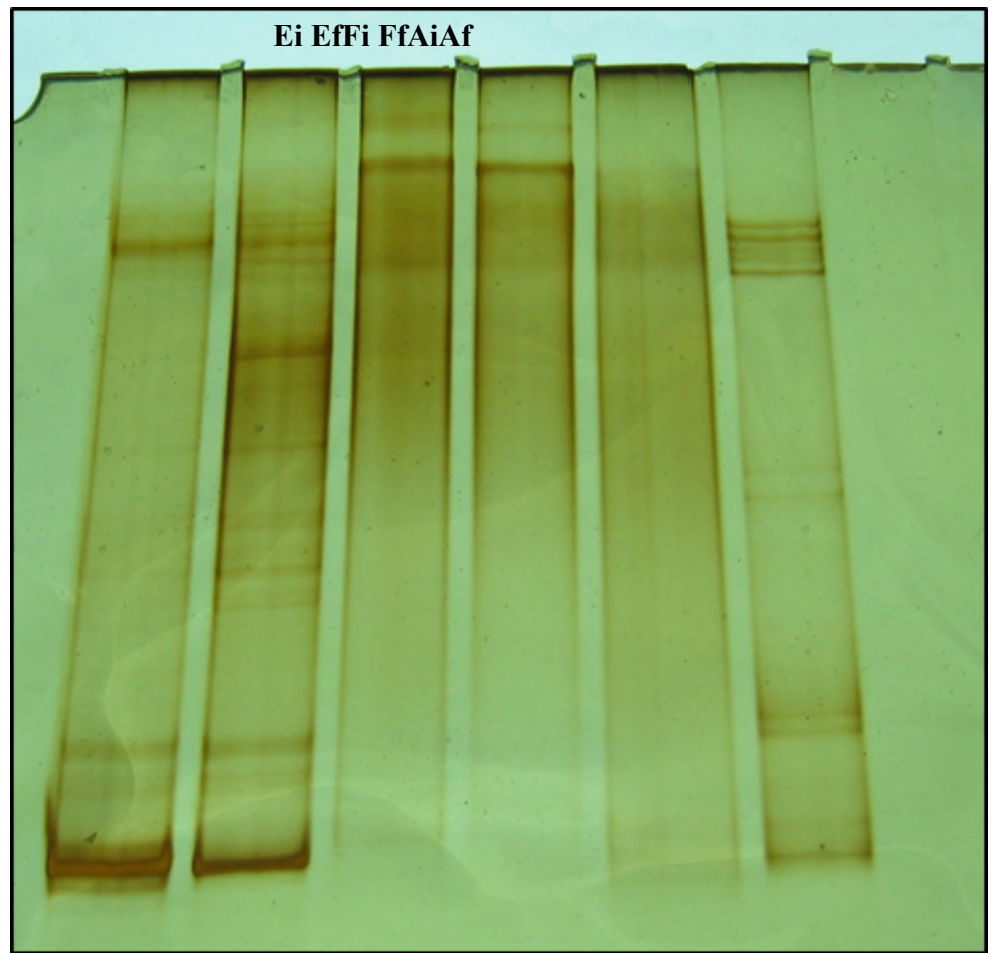

Fig. 5 Eubacteria, Fungi e Archaea in Test A (at the beginning and at the end). 

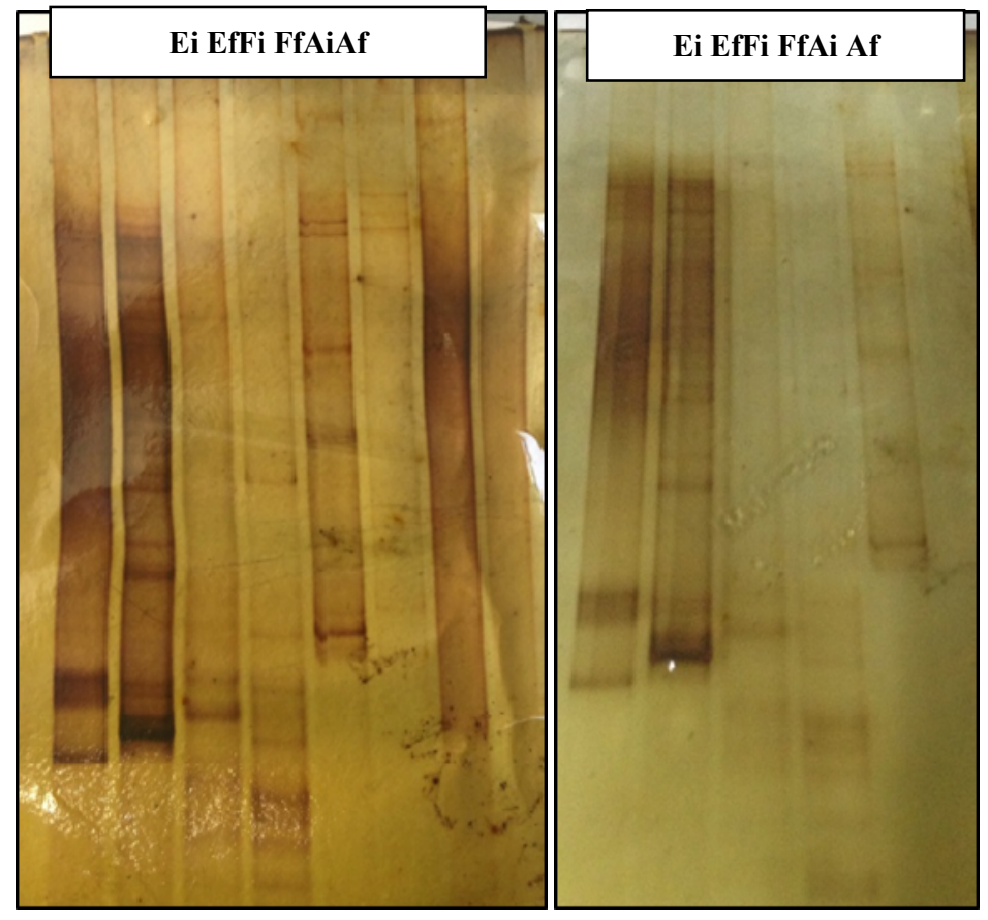

Fig. 6 Eubacteria, Fungi e Archaea in the Test B (on the left) and C (on the right) (at the beginning and at the end).

that in mesophilic conditions the microbial community which is present during the anaerobic digestion of the substrate consists of Clostridium, Actinobacteria, Gammaproteobacteria, Bacteroidetes, Deferribacteres, Methanosaeta and Methanosarcina.

Goberna et al. [24] studied the performance of two phases pomace methanogenic communities in co-digestion with cow manure. Through techniques Microarray and qPCR (quantitative PCR) obtained comparable results in Rincon et al. [23], confirming that the methanogenic communities acting in the substrate residue consists mainly of Methanosaeta. Specifically in the mix consisting of substrate and manure microorganisms of the species Methanosarcina, Methanoculleus, Methanobacterium, Methanobrevibacter and Methanosphaera were also detected.

Whereas the starting substrate, two-phase pomace, and the process conditions (in mesophilic anaerobic reactor, 35th) in the work are similar with respect to the work of Ntougias et al. [22], Rincon et al. [23], Goberna et al. [24], it can be assumed that the species displayed on SSCP in Figs. 5 and 6 are similar to those reported in literature.

\subsection{Seed Germination Test}

The seed germination test of plant organisms model of digestate was made on samples of the effluent of the test B, that, for the purpose of the work it was more efficient in terms of yield of methane and reaction speed.

Tests were carried out for the germination of plant species which are sensitive to rapid growth, Cucumissativus (Fig. 7), Lactuca sativa (Fig. 8) and Avena sativa (Fig. 9) and the main results are shown in the Tables 3-5. The data were processed through the statistical program R applying the Bonferrani Test: At the same letters are not significantly different averages correspond $(n=30, p=0.05)$.

Dilutions were made with distilled water, 1:5, 1:10 to $1: 20$ and it was found that already at a digestate dilution $1: 5$ is not toxic. For this reason, in the paper, it shows the results obtained during the test with 1:5 dilution, which coincides with the data of distilled water, and during the test in which it was used as it is digested. Germination tests were performed on filter paper and 


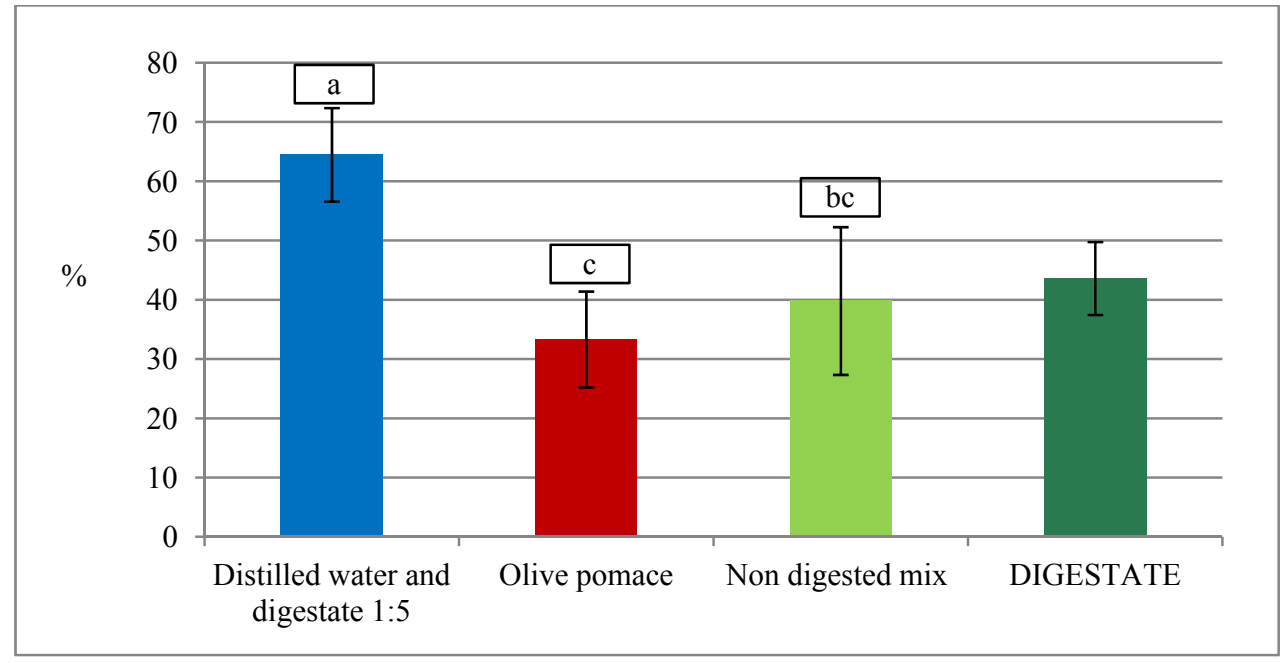

Fig. 7 Germination test of Cucumissativus, Digestate slightly inhibits germination seeds where as non digested and original pomace mainly does it.

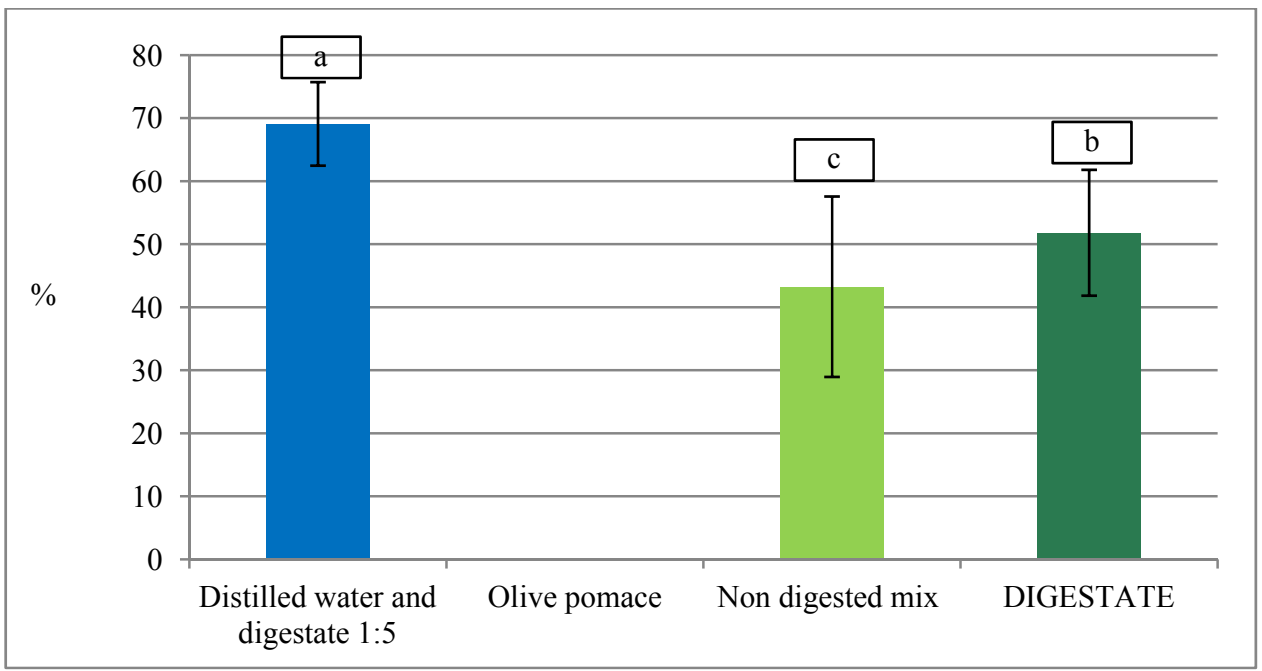

Fig. 8 Germination test of Lactuca sativa, Digestate slightly inhibits germination seeds whereas olive pomace totally does it.

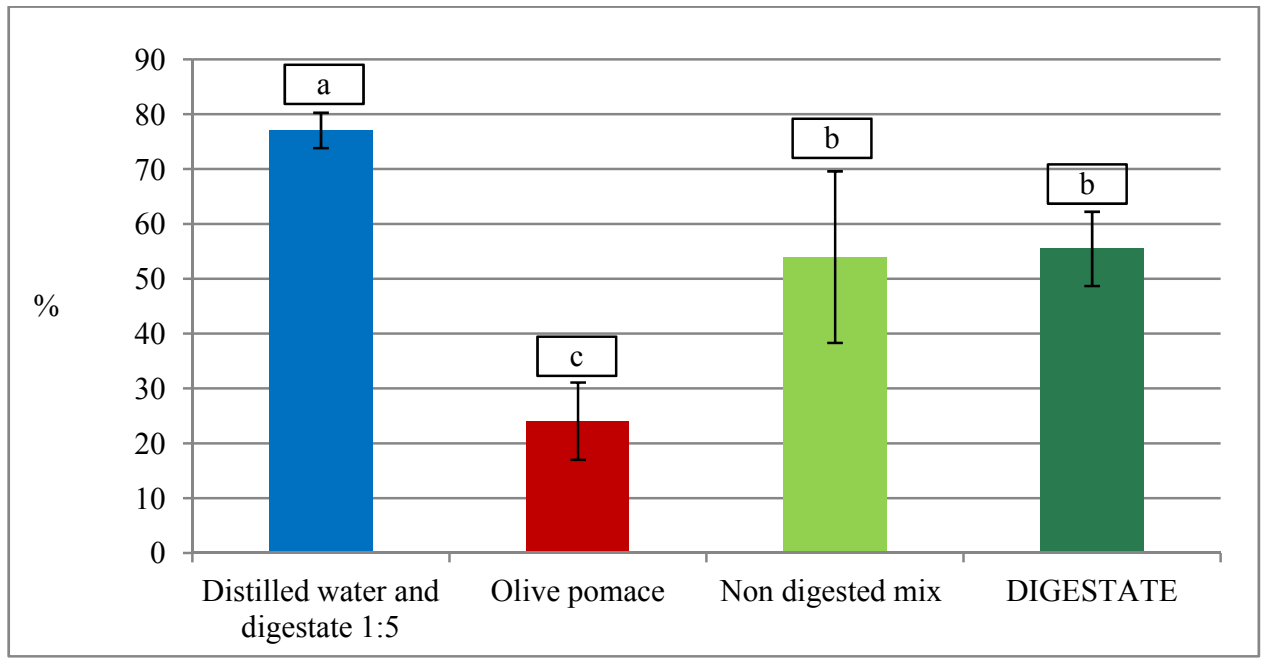

Fig. 9 Germination test of Avena sativa there is no significant different between non digested and digestate, whereas original pomace mainly inhibits the germination seeds. 
Table 3 Inhibition rate and average length of 30 seeds' roots of Cucumissativus.

\begin{tabular}{lll}
\hline Treatment & \% INIB & Root's average length $(\mathrm{cm})$ \\
\hline Distilled water and Digestate 1:5 & 0 & 6.5 \\
DIGESTATE & 32.3 & 4.3 \\
Non digested Mix & 46.4 & 3.9 \\
Olive pomace & 50.0 & 3.3 \\
\hline
\end{tabular}

Table 4 Inhibition rate and average length of 30 seeds' roots of Lactuca sativa.

\begin{tabular}{lll}
\hline Treatment & \% INIB & Root's average length $(\mathrm{cm})$ \\
\hline Distilled water and Digestate 1:5 & 0 & 6.9 \\
DIGESTATE & 25.0 & 5.1 \\
Non digested Mix & 37.5 & 4.3 \\
Olive pomace & 98.1 & 0 \\
\hline
\end{tabular}

Table 5 Inhibition rate and average length of 30 seeds' roots of Avena sativa

\begin{tabular}{lll}
\hline Treatment & \% INIB & Root'saveragelenght $(\mathrm{cm})$ \\
\hline Distilled water and Digestate 1:5 & 0 & 7.7 \\
DIGESTATE & 28.0 & 5.5 \\
Non digested Mix & 30.0 & 5.3 \\
Olive pomace & 68.8 & 2.4 \\
\hline
\end{tabular}

Table 6 Determining of the pathogenic charge in the digestates examined.

\begin{tabular}{lll}
\hline MIX & E.coli ucf $/ \mathrm{g}$ & Salmonella \\
\hline A & $10^{2}$ & Absent \\
B & $10^{2}$ & Absent \\
C & 10 & Absent \\
\hline
\end{tabular}

on soil, with similar and comparable results. The tests on soil approach the real conditions of use of the digestate, which is why the statistical analysis was deepened on the results of the germination of soil with such digestate, 1:5 digestate, undigested substratemix and original two-phase olive pomace.

Table 3 shows the results obtained when testing with Cucumber: 30 seeds of selected species on soil in Petri dishes (three replicates for each) were planted.

It is evident that the germination of Cucumber seeds is inhibited mainly by the pomace [25], but the digestate and the undigested mix, although qualitatively different influence in a very similar the root growth.

In the case of Lactuca sativa germination is completely inhibited by the presence of the two phases olive pomace, while the digestate as it has a discrete value of germination, higher than that of the mix is not digested (Table 4) .
Avena sativa, notoriously a resistant species, which is able to grow even in adverse conditions do not show a high rate of inhibition in the presence of undigested mix and digestate, the values are equal. The index of inhibition observed in the presence of substrate is higher instead (Table 5) .

The index of germination medium of the three model plants of digestate as it is equal to $70 \%$. Digestate as it inhibits the growth of Cucumissativus, Lactuca sativa and Avena sativa in a lesser extent than the olive pomaceis observed in all cases. The 1:5 dilution allows a germination of $100 \%$ and reduces to zero the rate of inhibition.

The charge pathogens were measured in all samples. The mix A (source of inoculum) and B showed a higher charge of $E$. coli compared to the samples $C$, probably because in this mix there is more water than in $\mathrm{A}$ and in $\mathrm{C}$. There is no specific legislation governing the hygienic quality of the products 
involved, pomace and plant biomass. Therefore, reference was made to the Regulation CE n 1069/2009, as amended, for effluents of the process of the anaerobic digestion with a biogas production from by-products animal. The limit set by Reg. CE $n$ $1069 / 2009$, is to $5 \times 10^{3}$ in a gram for $E$. coli and absent in $25 \mathrm{~g}$ Salmonella. For this reason, it can be said that the microbial load of pathogens which is present in the digested analyzed is acceptable; during the anaerobic digestion a reduction of the charge of pathogens occurred, as described by Smith et al. [26] and Scaglia et al. [27], who report an initial charge of $10^{7} \pm 10^{8} \mathrm{cfu} / \mathrm{g}$ for $E$. coli and $81 \pm 2 \mathrm{MPN} \mathrm{g} / \mathrm{dm}$ for Salmonella, therefore the digestate can be used in the field as fertilizer or compost.

\section{Conclusions}

The results of the tests $\mathrm{A}, \mathrm{B}$ and $\mathrm{C}$ allow to deduce a positive judgment on whether to bring full-scale processes conducted in laboratory scale; the tests performed provide the basis for further experiments regarding the methanogenic potential of not pitted pomace two phases and the concept of "exploitation" of industrial waste, otherwise treated as waste. It was shown that a mixture containing a substrate rich in methanogenic like the mud civil wastewater, pomace and vegetable matrices (Test A) to use as the power of the digester, serves as inoculum, because it provides a methanogenic population adapted to the substrates, and it is effective for initiating the following fermentations; the concept of the inoculum is also usable in Continuous Digesters. All tests examined have given good results compared to those reported in literature [28-31]. It should be emphasized that the step of sampling the inoculum is determinant in the start of the fermentation and for the optimum production of methane.

Furthermore, tests were performed germination of plant organisms model and analysis of the charge of the pathogens present in the effluent of the anaerobic digestion process. The results obtained suggest that the digestate output has the characteristics of suitability to be used as a soil amendment (the charge of pathogens is acceptable) and does not harm the crops to which it is subjected when diluted 1:5 with water.

In the work, a molecular analysis of the microbial community present during anaerobic digestion was initiated and a representative image, by SSCP technique, of the diversity of microorganisms active and linked by relationships syntrophic was given [3]. Understanding the role that specific microorganisms play and being able to identify, then through using molecular techniques, it is useful to deepen the knowledge of the process and optimize the performance of the anaerobic digestion of the substrate [23]. In conclusion, it can be said that:

- The use of an inoculum prepared ad hoc, starting from the digestate output from an anaerobic treatment of the same biomass to be used for the digestion in continuous, it is essential, so that the methanogenic microorganisms, are already adapted to the conditions of reactor that those nutrients, can ensure a better and more rapid biodegradation of the organic matter;

- The study of the dynamics of the microbial population using molecular techniques, especially those methanogenic species, provides useful information about the process. DGGE and FISH techniques or through comparison of profiles in the database, can be useful to optimize the yield of digestion, in that, to obtain more information on the characteristics of the active species allows to recreate the optimal conditions for the growth of certain microorganisms and increase the production of methane;

- It was observed a reduction of the charge of the pathogens after fermentation [27]. The germination test on plants useful model was played to assess the $\%$ inhibition of original digestate than the original pomace and the results show a slight growth inhibition for the original digestate, while the rate of inhibition of pomace as such is greater in all cases [25]. No 
inhibition was detected on digestate diluted (1:5) (Fig. 6 ). Then, the digestate output from the two-phase olive pomace anaerobic digestion has the characteristics of suitability for use as a soil amendment;

- Testing new mixtures with husk and plant biomass in the area, it allows the authors to offer alternative solutions to the problem of pollution, seasonality and storage of products and it allows mills to ensure continuous functionality of digesters, with significant cost savings and energy.

\section{Acknowledgments}

The authors gratefully acknowledge the members of Project OLIGAS for collaborations.

\section{References}

[1] Intini, F., Kuhtz, S., and Rospi, G. 2011. "Energy Recovery of the Solid Waste of the Olive Oil Industries-LCA Analysis and Carbon Footprint Assessment." Journal of Sustainable Energy and Environment 2: 157-66.

[2] Weiland, P. 2010. "Biogas Production: Current State and Perspectives." Applied Microbiology and Biotechnology 85: 849-60.

[3] Zieminski, K., and Frac, M. 2012. "Methane Fermentation Process as Anaerobic Digestion of Biomass: Transformations, Stages and Microorganisms." African Journal of Biotechnology 11: 4127-39.

[4] Labatut, A. R., Angenent, L. T., and Scott, R. N. 2011. "Biochemical Methane Potential and Biodegradability of Complex Organic Substrates." Bioresource Technology 102: 2255-64.

[5] Wang, Y., Gabbard, D. H., and Pai, P. 1991. "Inhibition of Acetate Methanogenesis by Phenols." Journal of Environmental Engineering 117: 487-500.

[6] Azbar, N., Keskin, T., and Yuruyen, A. 2008. "Enhancement of Biogas Production from Olive Mill Effluent (OME) by Co-digestion." Biomass and Bioenergy 32: 1195-201.

[7] Fantozzi, F., and Buratti, C. 2009. "Biogas Production from Different Substrates in an Experimental Continuously Stirred Tank Reactor Anaerobic Digester." Bioresource Technology 100: 5783-9.

[8] Jury, C., Benetto, E., Koster, D., Schmitt, B., and Welfring, J. 2010. "Life Cycle Assessment of Biogas Production by Monofermentation of Energy Crops and Injection Into the Natural Gas Grid." Biomass and
Bioenergy 34: 54-66.

[9] Griffin, E. M., McMahon, K. D., Mackie, R. I., and Raskin, L. 1998. "Methanogenic Population Dynamics during Start-Up of Anaerobic Digesters Treating Municipal Solid Waste and Biosolids.” Biotechnology and Bioengineering 57 (3): 342-55.

[10] Angelidaki, I., and Ahring, B. K. 1997. "Codigestion of Olive Oil Mill Wastewaters with Manure, Household Waste or Sewage Sludge." Biodegradation 8: 221-6.

[11] Zhang, B., Zhang, L. L., Zhang, S. C., Shi, H. Z., and Cai, W. M. 2005. "The Influence of $\mathrm{pH}$ on Hydrolysis and Acidogenesis of Kitchen Wastes in Two-Phase Anaerobic Digestion." Environmental Technology 26: 329-40.

[12] Teglia, C., Tremier, A., and Martel, J. L. 2011. "Characterization of Solid Digestates: Part 1, Review of Existing Indicators to Assess Solid Digestates Agricultural Use." Waste and Biomass Valorization 2: 43-58.

[13] Sahlstrom, L. 2003. "A Review of Survival of Pathogenic Bacteria in Organic Waste Used in Biogas Plants." Bioresource Technology 87: 161-6.

[14] Bendixen, H. F. 1999. "Hygienic Safety Results of Scientific Investigation in Denmark Sanitation Requirements in Danish BGPs." In Proceedings of the IEA workshop, 27-47.

[15] European Regulation: Regulation (EC) No 1069/2009 of the European Parliament and of the Council of 21 October 2009 laying down health rules as regards animal by-products and derived products not intended for human consumption and repealing Regulation (EC) No 1774/2002.

[16] Singleton, V. L., and Rossi, J. A. 1965. "Colorimetry of Total Phenolics with Phosphor Molybdic-Phosphotungstic Acid Reagents." American Journal of enology and Viticulture 16: 144-58.

[17] Lane, D. J., Pace, B., Olsen, G. J., Stahl, D. A., Sogin, M. L., and Pace, N. R. 1985. "Rapid Determination of 16S Ribosomal RNA Sequences for Phylogenetic Analyses." Proc. Natl. Acad. Sci. USA 82: 6955-9.

[18] Chachkhiani, M., Dabert, P., Abzianidze, T., Partskhaladze, G., Tsiklauri, L., Dudauri, T., and Gobon, J. J. 2004. "16S rDNA Characterisation of Bacterial and Archaeal Communities During Start-Up of Anaerobic Thermophilic Digestion of Cattle Manure." Bioresource Technology 93: 227-32.

[19] Di Giacomo, M., Paolino, M., Silvestro, D., Vigliotta, G., Imperi, F., Visca, P., Alifano, P., and Parente, D. 2007. "Microbial Community Structure and Dynamics of Dark Fire-Cured Tobacco Fermentation." Appl. Environ Microbiol 73: 825-37.

[20] Sambrook, J., and Russell, D. W. 2001. Molecular Cloning: A Laboratory Manual. 3rd edition. New York: Cold Spring Harbor Laboratory Press, Cold Spring 
Harbor.

[21] Fabbri, C., Soldano, M., Moscatelli, G., and Piccinni, S. 2012. "Biomassa, Come si Calcola il suo Valore Economic.” Supplemento A L'Informatore Agrario 13-7.

[22] Ntougias, S., Bourtzis, K., and Tsiamis, G. 2013. "The Microbiology of Olive Mills Wastes.” Biomed Research International 1: 1-16.

[23] Rincon, B., Borja, R., Gonzalez, J. M., Portillo, M. C., and Saiz-Jimenez, C. 2006. "Influence of Organic Loading Rate and Hydraulic Retention Time on the Performance, Stability and Microbial Communities of One-Stage Anaerobic Digestion of Two-Phase Olive Mill Solid Residue." Biochemical Engineering Journal 40: 253-61.

[24] Goberna, M., Gadermaier, M., García, C., Wett, B., and Insam, H. 2010. "Adaptation of Methanogenic Communities to the Cofermentation of Cattle Excreta and Olive Mill Wastes at $37{ }^{\circ} \mathrm{C}$ and $55{ }^{\circ} \mathrm{C}$." Applied and Environmental Microbiology 76: 6564-71.

[25] Cerfeda, A., Tommasi, L., Negro, C., De Bellis, L., and Miceli, A. 2006. "Spargimento dei Reflui Oleari: un Metodo per Valutarne L'impatto." L'Informatore Agrario
46: 40-2.

[26] Smith, S. R., Lang, N. L., Cheung, K. H. M., and Spanoudaki, K. 2005. "Factors Controlling Pathogen Destruction during Anaerobic Digestion of Biowastes." Waste Management 25: 417-25.

[27] Scaglia, B., D'Imporzano, G., Garuti, G., Negri, M., and Adani, F. 2014. "Sanitation Ability of Anaerobic Digestion Performed at Different Temperature on Sewage Sludge." Science of the Total Environment 466: 888-97.

[28] Tekin, A. R., and Dalgiç, A. C. 2000. "Biogas Production from Olive Pomace. Resource, Conservation and Recycling 30: 301-13.

[29] Agdag, O. N. 2011. "Biodegradation of Olive-Mill Pomace Mixed with Organic Fraction of Solid Waste." Biodegradation 22: 931-8.

[30] Danieli, L., and Aldrovandi, A. 2011. "Sostituire le colture Energetiche con le Biomasse ad hoc." Supplemento a L'informatore Agrario 38: 25-8.

[31] Borja, R., Rincón, B., Raposo, F., Alba, J., and Martin, A. 2002. "A Study of Anaerobic Digestibility of Two-Phases Olive Mill Solid Waste (OMSW) at Mesophilic Temperature." Process Biochemistry 38: 733-42. 